Article

\title{
Enterotoxigenic Escherichia coli Flagellin Inhibits TNF-Induced NF-KB Activation in Intestinal Epithelial Cells
}

\author{
Gaochan Wang ${ }^{1}$, Brian V. Geisbrecht ${ }^{2}$, Christian Rueter ${ }^{3}$ and Philip R. Hardwidge ${ }^{1, *}$ \\ 1 Department of Diagnostic Medicine/Pathobiology, Kansas State University, Manhattan, KS 66506, USA; \\ gaochan.wang@gmail.com \\ 2 Department of Biochemistry and Molecular Biophysics, Kansas State University, Manhattan, KS 66506, USA; \\ GeisbrechtB@ksu.edu \\ 3 Institute of Infectiology, Center for Molecular Biology of Inflammation, University of Muenster, \\ Muenster 48149, Germany; rueterchristian@hotmail.com \\ * Correspondence: hardwidg@vet.k-state.edu
}

Academic Editor: Lawrence S. Young

Received: 19 April 2017; Accepted: 14 May 2017; Published: 17 May 2017

\begin{abstract}
Enterotoxigenic Escherichia coli (ETEC) causes childhood diarrhea in developing countries. ETEC strains produce the heat-labile enterotoxin (LT) and/or heat-stable enterotoxins (ST) and encode a diverse set of colonization factors used for adherence to intestinal epithelial cells. We previously found that ETEC secretes a heat-stable protein we designated as ETEC Secreted Factor (ESF) that inhibits the extent of NF- $\mathrm{KB}$ activation normally induced by tumor necrosis factor alpha (TNF). Here we fractionated ETEC supernatants using fast protein liquid chromatography (FPLC) and determined that ETEC flagellin was necessary and sufficient to protect $I \kappa B \alpha$ from degradation in response to TNF stimulation. These data suggest a potentially novel mechanism by which ETEC may evade the host innate immune response by down-regulating NF-kB-dependent host responses.
\end{abstract}

Keywords: ETEC; flagellin; NF-kB

\section{Introduction}

Enterotoxigenic Escherichia coli (ETEC) causes travelers' diarrhea and diarrheal disease in children living in developing countries [1,2]. ETEC strains encode two main types of virulence factors-heat-labile and/or heat-stable toxins (LT and ST) - that cause watery diarrhea [3] and colonization factors (CFs) that mediate ETEC adherence to intestinal enterocytes [4]. In addition to causing diarrhea, LT enhances ETEC adherence to host cells by activating host signaling pathways, and inhibits antimicrobial peptide and cytokine (e.g., IL-8) production by disrupting nuclear factor- $\kappa \mathrm{B}$ (NF-kB) signaling pathway activation [5].

Flagella play critical roles in ETEC virulence [6]. For example, in addition to their role in bacterial motility, flagella promote ETEC attachment to intestinal epithelial cells [7] and affect biofilm formation [8]. EtpA, an exoprotein adhesin, mediates ETEC adhesion between flagella and host cells [9].

NF- $\mathrm{KB}$ plays an important role in regulating inflammation and innate immune responses to microbial infections [10]. NF- $\mathrm{KB}$ is normally sequestered in the cytoplasm by the NF- $\mathrm{kB}$ inhibitor, I $\kappa \mathrm{B} \alpha$. Upon TNF stimulation or microbial infection, the IкB kinase (IKK) complex is activated and phosphorylates I $\mathrm{I} B \alpha$ which is then polyubiquitinated and degraded, resulting in nuclear translocation of NF- $\mathrm{kB}$ subunits [11]. The innate immune system recognizes pathogens through a diverse set of cellular pattern recognition receptors [12]. Pathogens have accordingly evolved mechanisms to subvert innate signaling pathways to promote their survival and transmission [13]. 
We previously reported that pre-incubation of HCT-8 cells with ETEC H10407 supernatant prevented TNF stimulation from inducing $I \kappa B \alpha$ degradation and NF- $\kappa B$ activation [14]. We attributed this result to a heat-stable protein we designated as ETEC Secreted Factor (ESF). Here we fractionated ETEC supernatants and identified flagellin as necessary and sufficient for this phenomenon.

\section{Results and Discussion}

\subsection{ETEC H10407 Secretes ESF into M9 Minimal Media}

We previously found that ETEC H10407 secretes a heat-stable protein (ETEC Secreted Factor or ESF) into RPMI 1640 medium that subsequently inhibits the ability of TNF to activate NF- $\kappa B$ signaling [14]. To facilitate identification of this protein using biochemical fractionation, we first determined whether this factor was also secreted into the ETEC supernatant when ETEC was grown in M9 minimal medium. We incubated HCT-8 cells with either cell-free ETEC-M9 or ETEC-RPMI 1640 supernatants for $1.5 \mathrm{~h}$ and then treated the cells with TNF $\alpha$ ( $20 \mathrm{ng} / \mathrm{mL}, 20 \mathrm{~min})$. Pre-incubating HCT-8 cells with ETEC-M9 supernatant significantly inhibited $\mathrm{I} \kappa \mathrm{B} \alpha$ degradation in response to TNF $\alpha$ stimulation (Figure 1A), similar to the results obtained from pretreating HCT-8 cells with ETEC-RPMI 1640 supernatant (Figure 1B; [14]). IKB $\alpha$ degradation was not observed in cells pre-incubated with only ETEC-RPMI 1640 or ETEC-M9 supernatants in the absence of TNF (Figure 1C). These data indicated that ETEC H10407 also secretes the ESF into M9 minimal medium.

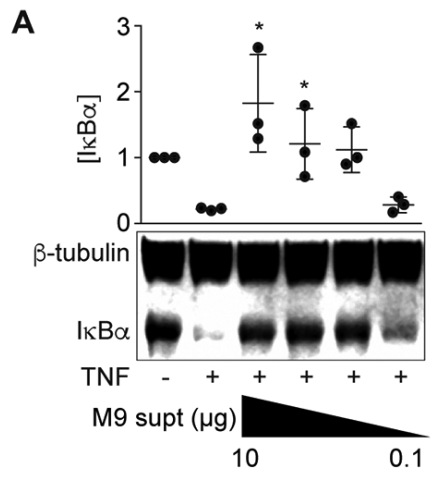

D

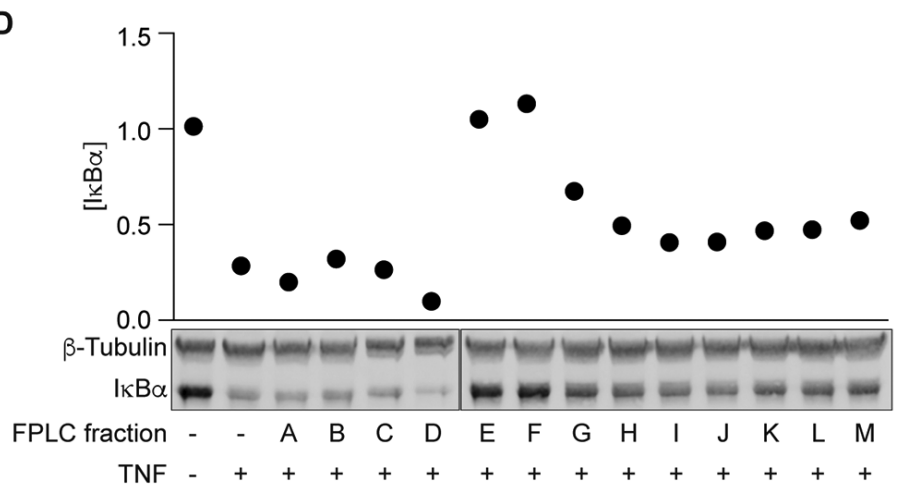

B

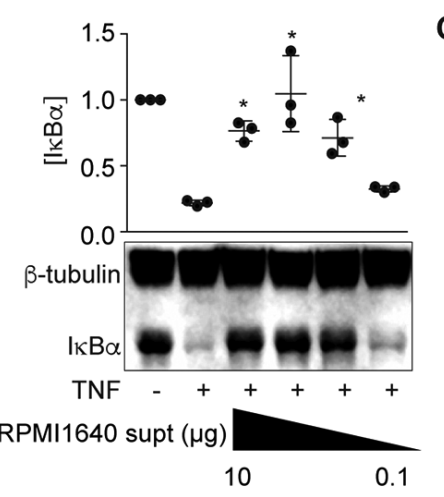

E

C

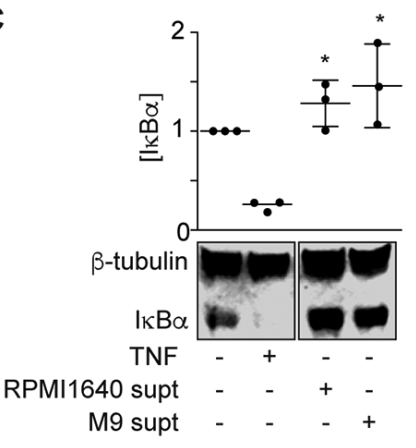

E

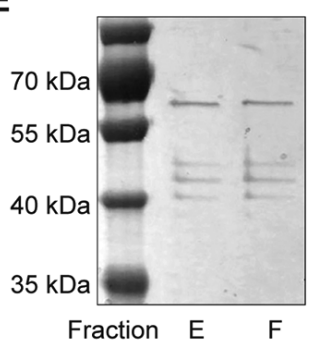

Figure 1. ESF fractionation and identification. (A) $\mathrm{I} \kappa \mathrm{B} \alpha$ immunoreactivity after incubating HCT-8 cells with ETEC H10407-M9 supernatant (0.1-10 $\mu \mathrm{g}$ protein) and then stimulating the cells with TNF (20 ng/mL, $20 \mathrm{~min}$ ) Asterisks indicate significantly different $\mathrm{I} \kappa \mathrm{B} \alpha$ abundance as compared with the 'TNF only' lane; (B) IкB $\alpha$ immunoreactivity after incubating HCT-8 cells with ETEC H10407-M9 supernatant (0.1-10 $\mu$ g protein) and then stimulating the cells with TNF (20 ng/mL, $20 \mathrm{~min})$; (C) I $k \mathrm{~B} \alpha$ immunoreactivity after incubating HCT-8 cells with ETEC H10407-RPMI1640 and ETEC H10407-M9 supernatants (10 $\mu \mathrm{g}$ protein) without TNF; (D) I $\mathrm{KB} \alpha$ immunoreactivity after incubating HCT- 8 cells with ETEC H10407-M9 supernatant FPLC fractions for $1.5 \mathrm{~h}$ and then stimulating the cells with TNF (20 ng/mL, $20 \mathrm{~min})$; (E) Sliver staining of FPLC fractions E and F on 10\% SDS-PAGE. 
Next, we used FPLC to fractionate ETEC-M9 supernatants and then assayed the fractions for their ability to block TNF-induced NF-kB activation. Two fractions (Figure 1D, fractions E and F) inhibited I $\kappa \mathrm{B} \alpha$ degradation in HCT- 8 cells and silver staining data showed that these two fractions had a similar protein composition (Figure 1E). We excised these bands and identified the proteins using mass spectrometry (Table 1). We identified a major outer membrane lipoprotein, outer membrane protein A, the flagellar hook-associated protein FliD, and flagellin (FliC). E. coli K-12 strains do not encode the ESF [14]. The two outer membrane proteins are highly conserved between ETEC and E. coli $\mathrm{K}-12$, but FliC and FliD are not ( $50 \%$ identity). We therefore focused on FliC and FliD for subsequent biochemical assays.

Table 1. Mass spectrometry results.

\begin{tabular}{llcc}
\hline \multicolumn{1}{c}{ Protein Candidates } & Sequence Coverage & Identity to E. coli MG1655 & GenBank Accession \# \\
\hline $\begin{array}{l}\text { Major outer membrane } \\
\text { lipoprotein }\end{array}$ & $49 \%$ over 78 AAs & $100 \%$ & CBJ00536.1 \\
$\begin{array}{l}\text { Outer membrane protein A } \\
\text { Flagellar hook-associated }\end{array}$ & $26 \%$ over 346 AAs & $99 \%$ & CBJ01214.1 \\
protein 2 (FliD) & $44 \%$ over 470 AAs & $50 \%$ & CBJ01536.1 \\
Flagellin (FliC) & $71 \%$ over 487 AAs & $52 \%$ & CBJ01535.1 \\
\hline
\end{tabular}

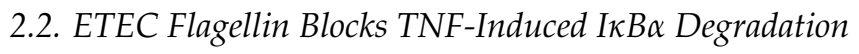

To examine whether FliC and/or FliD protect HCT-8 cells from TNF-induced NF-kB activation, we generated ETEC H10407 fliC and fliD mutants and prepared cell-free supernatants from these mutant strains in RPMI 1640. ETEC $\Delta$ fliC supernatants failed to block TNF-induced IkB $\alpha$ degradation (Figure 2A).

Complementing ETEC $\triangle f l i C$ with a fliC expression plasmid partially restored the protective phenotype ( $p=0.1$; Figure 2A). By contrast, the ETEC $\Delta f l i D$ supernatant behaved more similarly to the WT ETEC supernatant, though these data did not reach statistical significance ( $p=0.1$; Figure $2 \mathrm{~A}$ ). We therefore concluded that $f l i C$ expression was necessary for the ESF phenotype. We next determined whether recombinant FliC is sufficient to account for the ESF phenotype. We expressed ETEC FliC in E. coli BL21 (DE3) and purified the recombinant protein using Ni-NTA chromatography (Figure 2B). FliC blocked IкB $\alpha$ degradation in response to TNF in a dose-dependent manner (Figure 2C).

To eliminate the potential impact of LPS contamination, we also expressed and purified FliC from E. coli ClearColi 21 (DE3). The ClearColi strain incorporates seven genetic deletions that inhibit carbohydrate modifications of the LPS molecule. Recombinant proteins expressed from ClearColi BL21 (DE3) do not need removal of contaminating LPS to avoid TLR4 activation [15]. Pre-incubating HCT-8 cells with FliC purified from ClearColi also protected IкB $\alpha$ from TNF-induced degradation in a dose-dependent manner (Figure 2D). The protective phenotype mediated by FliC was also heat-stable (Figure 2E), consistent with previous data [14].

To determine whether the FliC-mediated phenotype was abrogated by blocking Toll-like receptor 5 (TLR5) recognition, we first treated HCT-8 cells with the TLR5 antagonist hTLR5-Fc, followed by FliC and TNF. I $\kappa B \alpha$ degradation in response to TNF stimulation was still inhibited by ETEC FliC, even after hTLR5-Fc pre-incubation (Figure 2F). 
A
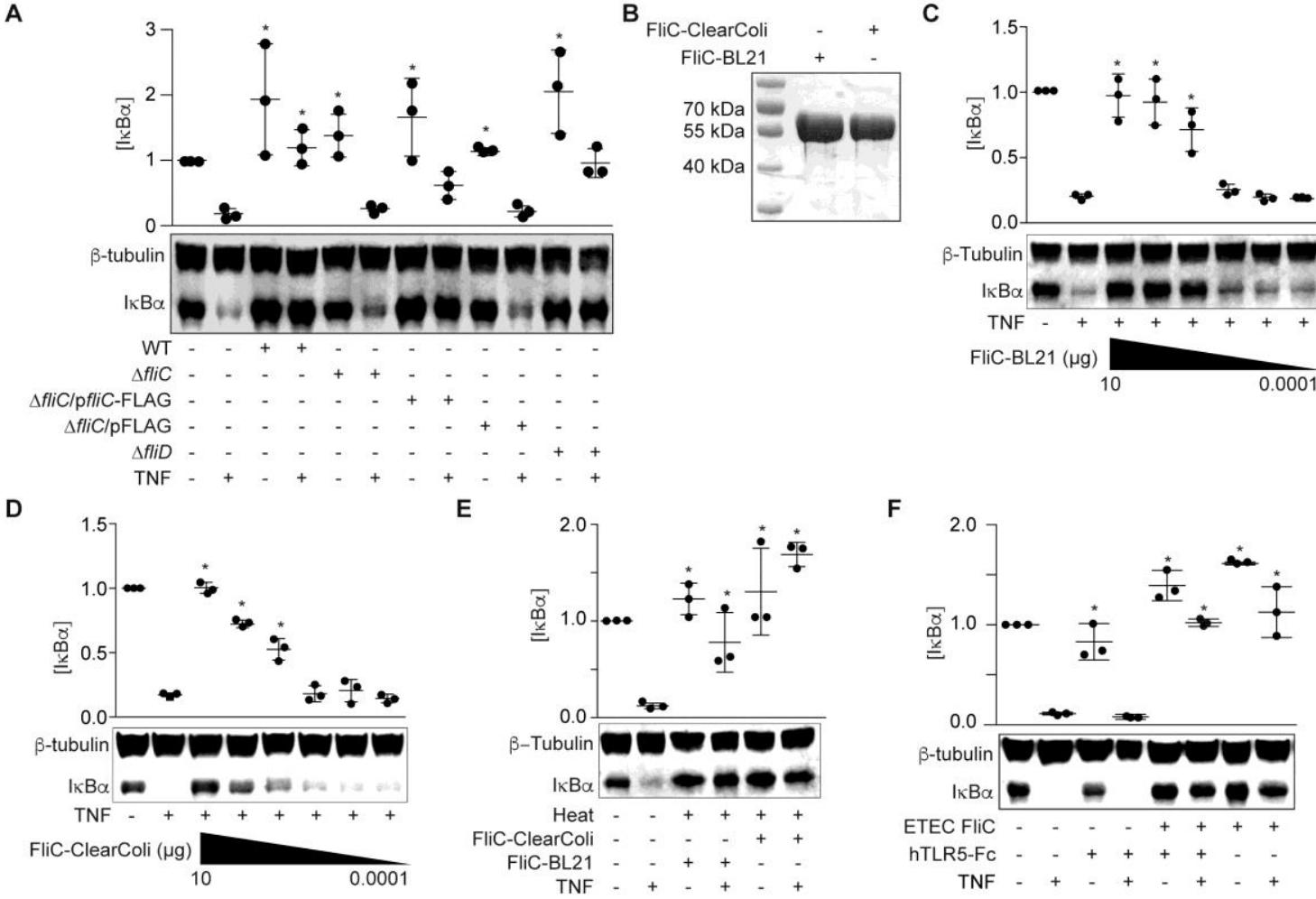

Figure 2. ETEC FliC blocks TNF-induced $I \kappa B \alpha$ degradation. (A) I $\mathrm{K} B \alpha$ immunoreactivity after incubating HCT- 8 cells with WT and mutant ETEC supernatants (10 $\mu \mathrm{g}$ protein) and then stimulating the cells with TNF (20 ng/mL, $20 \mathrm{~min}$ ); (B) Purified recombinant FliC resolved using 10\% SDS-PAGE and Coomassie blue staining; (C) IкB $\alpha$ immunoreactivity after incubating HCT- 8 cells with FliC-pET28a-BL21 (100 pg-10 $\mu \mathrm{g}$ ) for $1.5 \mathrm{~h}$ followed by TNF stimulation $(20 \mathrm{ng} / \mathrm{mL}, 20 \mathrm{~min})$; (D) I $\kappa \mathrm{B} \alpha$ immunoreactivity after incubating HCT-8 cells with FliC-pET28a-ClearColi $(100 \mathrm{pg}-10 \mu \mathrm{g})$ for $1.5 \mathrm{~h}$ and then stimulating the cells with TNF (20 ng/mL, $20 \mathrm{~min})$; (E) IKB $\alpha$ immunoreactivity after incubating HCT- 8 cells with heated $\left(100{ }^{\circ} \mathrm{C}, 20 \mathrm{~min}\right)$, recombinant FliC $(1 \mu \mathrm{g})$ for $1.5 \mathrm{~h}$ followed by TNF stimulation (20 ng/mL, $20 \mathrm{~min}$ ); (F) IKB $\alpha$ immunoreactivity after pretreating HCT-8 cells with $1.5 \mu \mathrm{g} / \mathrm{mL}$ hTRL5-Fc for $1 \mathrm{~h}$, followed by FliC (100 ng/mL, $90 \mathrm{~min})$ and TNF (20 ng/mL, $20 \mathrm{~min})$.

\subsection{FliC Domain Mapping}

The function of flagellin is broadly conserved among all flagellated bacteria. Nevertheless, outside the $\mathrm{N}$ - and C-terminal regions that comprise its intramolecular coiled-coil, the flagellin (FliC) protein itself exhibits localized sequence/structure variability between otherwise closely related bacteria. For example, whereas the central region of Salmonella FliC contains two distinct 100 residue domains [16], sequence analyses suggest that ETEC FliC contains only a single, fused central domain consisting of residues 176-395. Importantly, residues within this central region of E. coli flagellin comprise variable $\mathrm{H}$ serotype-specific epitopes [6], suggesting that these sequences could impart strain-specific activities to the FliC protein.

To investigate if a specific FliC subdomain might account for the $\mathrm{I} \kappa \mathrm{B} \alpha$ protective phenotype, we overexpressed and purified three truncated FliC proteins designated as FliC(1-395), FliC(176-395), and FliC(176-488) (Figure 3A). These proteins were expressed from pT7HMT to facilitate removal of the $\mathrm{N}$-terminal His-tag using TEV protease. While the presence of a His-tag did not affect the activity of full-length FliC in blocking IKB $\alpha$ degradation in response to TNF (Figure 3B), none of the truncated FliC proteins were active. As a control, both tagged- and untagged-FliC were heat-stable, consistent with the heat-stability of the ESF we described previously (Figure 3C, [14]). 
A

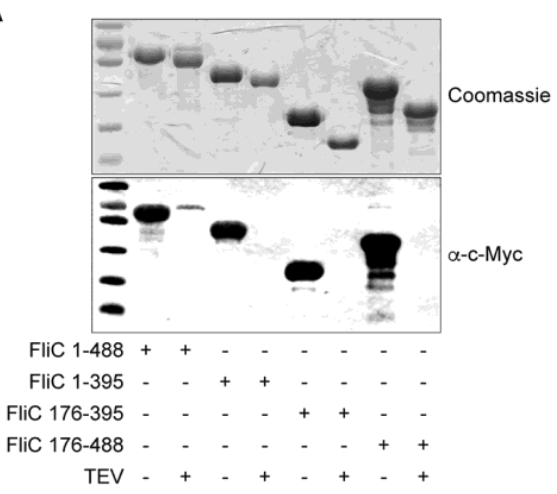

B

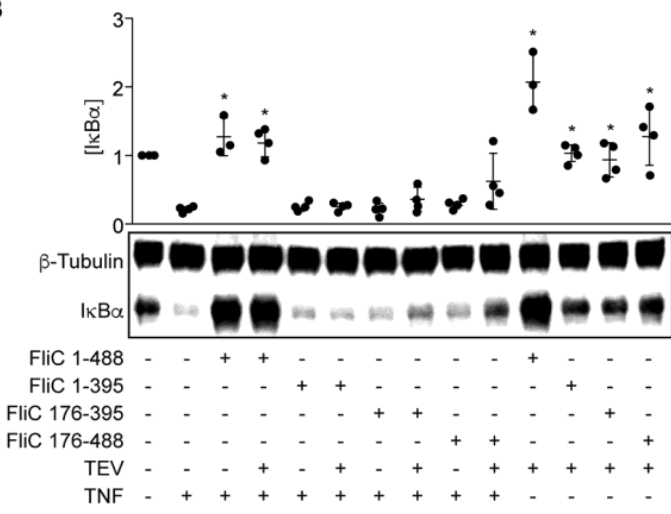

C

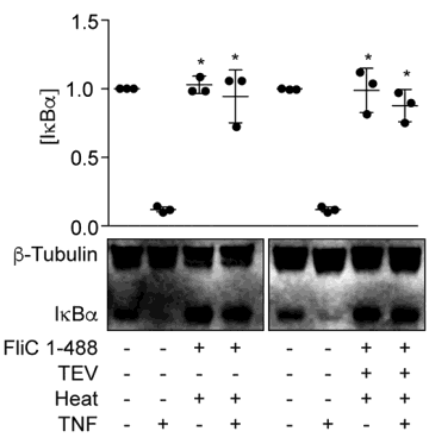

Figure 3. FliC truncations are inactive. (A) Purified FliC truncations +/ - TEV protease treatment were resolved using 10\% SDS-PAGE and analyzed by Coomassie blue staining (top) and Western blotting (bottom); (B) I $\mathrm{B} \alpha$ immunoreactivity after incubating HCT-8 cells with FliC truncations $(1 \mu \mathrm{g})$ for $1.5 \mathrm{~h}$ followed by TNF stimulation ( $20 \mathrm{ng} / \mathrm{mL}, 20 \mathrm{~min}$ ); (C) IкB $\alpha$ immunoreactivity after incubating HCT-8 cells with heated $\left(100{ }^{\circ} \mathrm{C}, 20 \mathrm{~min}\right)$ FliC $(1 \mu \mathrm{g})$ followed by TNF stimulation $(20 \mathrm{ng} / \mathrm{mL}, 20 \mathrm{~min})$.

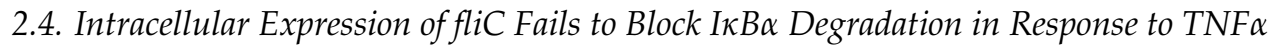

We next sought to determine whether mammalian expression of FliC would be sufficient to block TNF-induced IкB $\alpha$ degradation. We expressed FliC fragments from a mammalian cell expression vector and transfected these plasmids into HCT-8 cells (Figure 4A). The expressed proteins were not toxic to HCT-8 cells (Figure 4B), but they were unable to block TNF-induced IкB $\alpha$ degradation (Figure 4C).

Here we identified ETEC FliC as necessary and sufficient to inhibit $\mathrm{I} \kappa \mathrm{B} \alpha$ degradation in response to TNF stimulation (Figures 1 and 2). Surprisingly, blocking TLR5 recognition of flagellin did not eliminate this phenotype, suggesting a potential TLR5-independent mechanism of action (Figure 2). We were unable to define the FliC subdomain responsible for this activity, despite truncating the protein into soluble fragments that comprised the variable central domain (Figure 3). We also observed 
that endogenous expression of FliC in mammalian cells did not reconstitute this phenotype (Figure 4), suggesting a potential extracellular target for FliC.

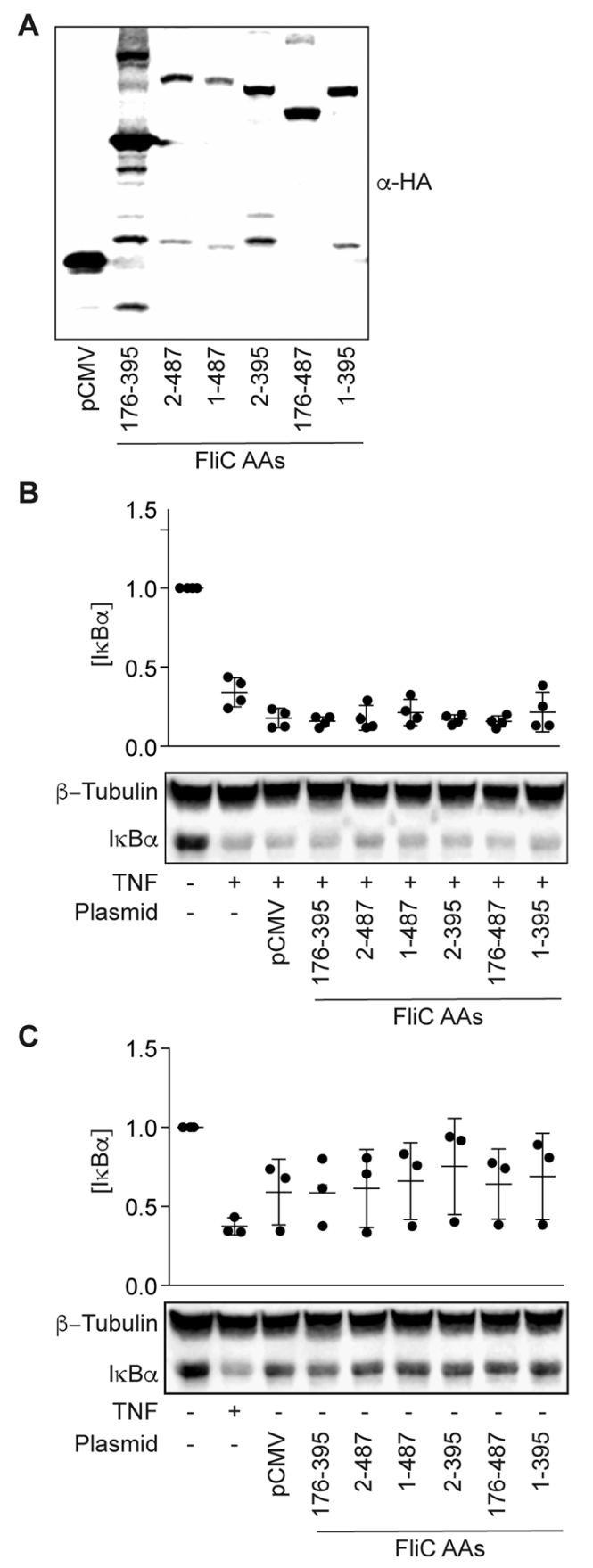

Figure 4. Intracellular expression of fliC fails to block $\mathrm{I} \kappa \mathrm{B} \alpha$ degradation in response to $\mathrm{TNF} \alpha$. (A) Immunoreactivity of transfected FliC truncations expressed in HCT-8 cells $24 \mathrm{~h}$ post-transfection; (B) IKB $\alpha$ immunoreactivity in HCT-8 cells $24 \mathrm{~h}$ post-transfection of $f l i C$ truncations in the absence of TNF stimulation; (C) I $\mathrm{KB} \alpha$ immunoreactivity in HCT- 8 cells 24 h post-transfection of $f l i C$ truncations after TNF stimulation (20 $\mathrm{ng} / \mathrm{mL}, 20 \mathrm{~min})$.

TNF-TNFR1-mediated NF- $\mathrm{BB}$ activation occurs on the cell surface and is associated with lipid rafts [17]. Cationic cell-penetrating peptides can disrupt TNF-mediated NF- $\kappa$ B signaling by inducing TNF receptor internalization in a clathrin-dependent manner [18]. 
The mechanism of FliC-mediated inhibition of IкB $\alpha$ degradation in response to TNF could be associated with TNFR internalization, as we had previously observed that blocking clathrin-dependent endocytosis affected the activity of the ETEC secreted factor (ESF; [14]). Future characterization of the phenotype we report here has the potential to provide insight to the development of anti-inflammatory compounds that target NF- $\mathrm{KB}$, an approach that might prove efficacious in treating autoimmune disorders. These data also reinforce the notion that bacterial pathogens have evolved mechanisms to subvert the activation of host innate signaling pathways.

\section{Materials and Methods}

\subsection{Reagents and Antibodies}

Antibiotics were purchased from Fisher Scientific (Waltham, MA, USA). Restriction enzymes were purchased from New England BioLabs (Ipswich, MA, USA). TNF $\alpha$ was purchased from Cell Signaling Technology (Beverly, MA, USA). hTLR5-Fc was purchased from InvivoGen (San Diego, CA, USA). Antibodies were purchased from the following sources: HA, FLAG, and c-Myc (Sigma, St. Louis, MO, USA), His and tubulin (Santa Cruz, Dallas, TX, USA), IkB $\alpha$ (Cell Signaling Technology).

\subsection{Bacterial Strains and Plasmids}

Bacterial strains and plasmids are described in Table 2. ETEC mutants were derived from wild-type ETEC H10407 [19]. E. coli DH5 $\alpha$ was used for routine molecular biological manipulations while E. coli BL21 (DE3) and ClearColi BL21 (DE3) were used for protein expression. Plasmids pKD3 and pKD46 were used to construct ETEC H10407 mutants. Plasmids pET28a and pT7HMT [20] were used to express recombinant proteins. All bacterial strains were grown aerobically in Luria-Bertani (LB) broth or on LB plates with antibiotics at $37^{\circ} \mathrm{C}$.

Table 2. Strains and plasmids used in this study.

\begin{tabular}{ccc}
\hline Strain or Plasmid & Description & Source or Reference \\
\hline ETEC H10407 & Strains & \\
E. coli DH5 $\alpha$ & O78:H11, CFA/I, LT ${ }^{+}$and ST & {$[19]$} \\
E. coli BL21 (DE3) & Cloning strain & New England BioLabs \\
ClearColi BL21 (DE3) & Protein overexpression strain & Novagen \\
ETEC $\Delta f l i C$ & Protein overexpression & Lucigen \\
ETEC $\Delta f l i D$ & ETEC H10407 fliC mutant & This study \\
ETEC $\Delta$ fliC/pFliC-FLAG & ETEC H10407 fliD mutant & This study \\
& ETEC H10407 $\Delta$ fliC complemented with fliC & This study \\
\hline pFLAG-CTC & Plasmids & \\
pET28a & FLAG-tagged protein expression & Sigma \\
pT7HMT & His ${ }_{6}$ fusion protein expression & Novagen \\
pKD3 & His ${ }_{6}$ fusion protein expression with TEV site & {$[20]$} \\
PKD46 & Template for mutagenic PCR products & {$[21]$} \\
pCMV & Lambda Red mediated mutagenesis & {$[21]$} \\
pET28a-FliC & Mammalian expression vector with HA-tag & {$[22]$} \\
pT7HMT-FliC & FliC in pET28a & This study \\
pT7HMT-FliC (176-395) & FliC in pT7HMT & This study \\
pT7HMT-FliC (1-395) & FliC (176-395) in pT7HMT & This study \\
pT7HMT-FliC (176-488) & FliC (1-395) in pT7HMT & This study \\
pCMV-FliC (1-487) & FliC (176-488) in pT7HMT & This study \\
pCMV-FliC (176-395) & FliC (1-487) in pCMV & This study \\
pCMV-FliC (1-395) & FliC (176-395) in pCMV & This study \\
pCMV-FliC (176-487) & FliC (1-395) in pCMV & This study \\
pCMV-FliC (2-395) & FliC (176-487) in pCMV & This study \\
pCMV-FliC (2-487) & FliC (2-395) in pCMV & This study \\
\hline & FliC (2-487) in pCMV & This study \\
\hline
\end{tabular}




\subsection{Cell Lines and Culture Conditions}

The intestinal epithelial cell line HCT- 8 was maintained at $37^{\circ} \mathrm{C}, 5 \% \mathrm{CO}_{2}$ in RPMI 1640 medium supplemented with $10 \%$ fetal bovine serum (FBS) and penicillin-streptomycin (100 U/mL). HCT-8 cells were seeded in 6-well plates at a concentration of $5 \times 10^{5}$ cells/well. Media was replaced with fresh RPMI 1640 lacking both FBS and penicillin-streptomycin prior to experimentation.

\subsection{ETEC Supernatant}

ETEC H10407 culture supernatants were prepared in either RPMI 1640 or in M9 minimal medium (M9 salts, $2 \mathrm{mM} \mathrm{MgSO}_{4}, 0.1 \mathrm{mM} \mathrm{CaCl}_{2}, 0.4 \%$ glucose). Cell-free supernatants were concentrated by using Centricon Plus-70 Centrifugal Filters (EMD Millipore, Billerica, MA, USA) with a membrane Normal Molecular Weight Limit (NMWL) of $3 \mathrm{kDa}$ and then precipitated using acetone. Protein pellets were collected by centrifugation at $15,000 \times g, 4{ }^{\circ} \mathrm{C}$ for $10 \mathrm{~min}$, and resuspended in $0.15 \mathrm{M} \mathrm{NaCl}$ for fast protein liquid chromatography analysis.

\subsection{Fast Protein Liquid Chromatography and Mass Spectrometry}

ETEC H10407 supernatants were fractionated using a AKTA Fast Protein Liquid Chromatography (FPLC) system (GE Life Sciences, Marlborough, MA, USA) to facilitate molecular characterization of the ESF. Acetone-precipitated supernatants from M9-grown ETEC cultures were resuspended in $10 \mathrm{~mL}$ $0.15 \mathrm{M} \mathrm{NaCl}$, clarified by $0.22 \mu \mathrm{m}$ filtration, and applied at $4 \mathrm{~mL} / \mathrm{min}$ to a Superdex S200 26/60 column (GE Life Sciences) that had previously been equilibrated in $20 \mathrm{mM}$ Tris (pH 8.0), $200 \mathrm{mM} \mathrm{NaCl}$. The ESF-containing eluent was collected from the column between $110-130 \mathrm{~mL}$, and dialyzed against $4 \mathrm{~L}$ of $20 \mathrm{mM}$ Tris ( $\mathrm{pH}$ 8.0) in preparation for further chromatography. The ESF-containing sample was applied to a $1 \mathrm{~mL}$ Resource $\mathrm{Q}$ anion exchange column (GE Life Sciences). The column was washed with $20 \mathrm{mM}$ Tris ( $\mathrm{pH}$ 8.0) until the $\mathrm{OD}_{280}$ value reach baseline, and then the bound proteins were eluted with a gradient to $1 \mathrm{M} \mathrm{NaCl}$ in the same buffer. Fractions of $1 \mathrm{~mL}$ were collected and then screened for their ability to prevent IкB $\alpha$ degradation in response to TNF, separated by SDS-PAGE, and detected using Silver Staining (Thermo Scientific, Waltham, MA, USA). Proteins from active fractions were excised and digested in-gel with trypsin (Promega, Madison, WI, USA). Proteins were identified using mass spectrometry at the Mass Spectrometry \& Analytical Proteomics Laboratory, University of Kansas.

\subsection{Construction of ETEC H10407 Mutants}

ETEC were generated using the Lambda Red Recombinase system [22]. PCR products containing chloramphenicol resistance cassettes were amplified from plasmid pKD3 using primers (Table 3) flanked with homologous upstream and downstream gene sequences. PCR products were transformed into ETEC H10407 carrying the pKD46 plasmid via electroporation. Potential mutants were screened on LB plates containing chloramphenicol. All mutants were confirmed using DNA sequencing. ETEC $\mathrm{H} 10407 \mathrm{fliC}$ was also expressed from pFLAG-CTC for complementation studies.

\subsection{Recombinant Protein Expression and Purification}

Recombinant protein expression was induced with $1 \mathrm{mM} \mathrm{IPTG}$, at $37^{\circ} \mathrm{C}$ for $5 \mathrm{~h}$. Recombinant proteins were purified by using nickel-affinity chromatography and subsequently dialyzed into PBS. Purified proteins were analyzed on $12 \%$ SDS-PAGE and concentrations were quantified using the Bradford method.

\subsection{Transfection}

HCT-8 cells were seeded in 6-well plates at a concentration of $2 \times 10^{5}$ cells/well, grown to $70-80 \%$ confluence, and transfected with $2.5 \mu \mathrm{g}$ plasmid DNA using Lipofectamine 3000 
(Life Technology, Carlsbad, CA, USA). Transfected cells were stimulated with TNF $\alpha(20 \mathrm{ng} / \mathrm{mL})$ at $12-48 \mathrm{~h}$ post-transfection.

Table 3. Oligonucleotides used in this study.

\begin{tabular}{|c|c|c|}
\hline Primer & Purpose & Sequence $\left(5^{\prime}-3^{\prime}\right)$ \\
\hline \multirow{2}{*}{ PRH-3427 } & \multirow{2}{*}{ Delete ETEC H10407 fliD } & $\mathrm{A}_{2} \mathrm{~T}_{2} \mathrm{GC}_{2} \mathrm{GATA}_{2} \mathrm{C}_{3} \mathrm{GCT}_{2} \mathrm{ATCTACTGT}_{3} \mathrm{GCA}_{2} \mathrm{TC}$ \\
\hline & & $\mathrm{A}_{4} \mathrm{G}_{2} \mathrm{~A}_{2} \mathrm{~T}_{2} \mathrm{AG}_{2} \mathrm{TGTGTA}_{2} \mathrm{CTG}_{2} \mathrm{AGCTGCT}_{2} \mathrm{C}$ \\
\hline \multirow{2}{*}{ PRH-3428 } & \multirow{2}{*}{ Delete ETEC H10407 fliD } & $\mathrm{T}_{2}$ GTGCATAG $_{2} \mathrm{CT}_{4}$ GAGC $_{2}$ GCTCGCG $_{2}$ TATAC \\
\hline & & $\mathrm{ATGCTGAC}_{2} \mathrm{TC}_{2} \mathrm{GTGA}_{2} \mathrm{TG}_{3} \mathrm{~A}_{2} \mathrm{~T}_{2} \mathrm{AGC}_{2} \mathrm{ATG}_{2} \mathrm{TC}_{2}$ \\
\hline PRH-3429 & Verify fliD deletion & $\mathrm{TCTCTC}_{2} \mathrm{TGT}_{6} \mathrm{CT}_{2} \mathrm{~A}_{2} \mathrm{CG}_{2} \mathrm{CT}$ \\
\hline PRH-3430 & Verify fliD deletion & $\mathrm{GCTGAT}_{2} \mathrm{GT}_{2} \mathrm{GTC}_{2} \mathrm{TGCATA}_{3} \mathrm{CA}$ \\
\hline \multirow{2}{*}{ PRH-3431 } & \multirow{2}{*}{ Delete ETEC H10407 fliC } & $\mathrm{CGTG}_{3} \mathrm{CA}_{2} \mathrm{CAGC}_{3} \mathrm{~A}_{2} \mathrm{TA}_{2} \mathrm{CATCA}_{2} \mathrm{GT}_{2} \mathrm{GTA}_{2} \mathrm{~T}_{2} \mathrm{GA}$ \\
\hline & & $\mathrm{TA}_{2} \mathrm{G}_{2} \mathrm{~A}_{4} \mathrm{GATCGTGTAG}_{2} \mathrm{CTG}_{2} \mathrm{AGCTGCT}_{2} \mathrm{C}$ \\
\hline \multirow{2}{*}{ PRH-3432 } & \multirow{2}{*}{ Delete ETEC H10407 fliC } & $\mathrm{GCG}_{3} \mathrm{CAGA}_{6} \mathrm{C}_{4} \mathrm{GC}_{2} \mathrm{G}_{2} \mathrm{TG}_{2} \mathrm{CG}_{5} \mathrm{~T}_{2}$ GAGCGA \\
\hline & & $\mathrm{TA}_{2} \mathrm{GTGTA}_{4} \mathrm{TG}_{3} \mathrm{~A}_{2} \mathrm{~T}_{2} \mathrm{AGC}_{2} \mathrm{ATG}_{2} \mathrm{TC}_{2}$ \\
\hline PRH-3433 & Verify fliC deletion & ATGATGCGCAGAGTAGAGT 2 GTAT \\
\hline PRH-3434 & Verify fliC deletion & $\mathrm{ATGAT}_{2} \mathrm{ATC}_{2} \mathrm{GT}_{3} \mathrm{CTGCAG}_{3} \mathrm{~T}_{2}$ \\
\hline PRH-3619 & Clone fliC pCMV-XhoI & $\mathrm{TAC}_{2} \mathrm{GCTCGAGATG}_{2} \mathrm{CACA}_{2} \mathrm{GTCAT}_{2} \mathrm{~A}_{2} \mathrm{TA}$ \\
\hline PRH-3620 & Clone fliC pCMV-NotI & $\mathrm{ATA}_{2} \mathrm{GA}_{2} \mathrm{TGCG}_{2} \mathrm{C}_{2} \mathrm{GCACGCAGCAGAGACAGTA}$ \\
\hline PRH-3681 & Clone fliC pET28a-Nde I & $\mathrm{GGA}_{2} \mathrm{~T}_{2} \mathrm{C}_{2} \mathrm{ATATG}_{2} \mathrm{CACA}_{2} \mathrm{GTCAT}_{2} \mathrm{~A}_{2} \mathrm{TACA}$ \\
\hline PRH-3682 & Clone fliC pET28a-XhoI & $\mathrm{TAC}_{2}$ GCTCGAGACGCAGCAGAGACAGTA \\
\hline PRH-3684 & Clone fliC pFLAG-CTC-XhoI & $\mathrm{TAC}_{2} \mathrm{GCTCGAG}_{2} \mathrm{CACA}_{2} \mathrm{GTCAT}_{2} \mathrm{~A}_{2} \mathrm{TA}$ \\
\hline PRH-3685 & Clone fliC pFLAG-CTC-BglII & $\mathrm{G}_{2} \mathrm{~A}_{2}$ GATCTACGCAGCAGAGACAGTA \\
\hline PRH-3788 & Clone fliC 176-395 pCMV-XhoI & $\mathrm{TATAT}_{2} \mathrm{ACTCGAG}_{2} \mathrm{ATG}_{2} \mathrm{CGCGCAGA}_{3} \mathrm{GCA}_{2}$ \\
\hline PRH-3789 & Clone fliC 176-395 pCMV-NotI & $\mathrm{ATA}_{2} \mathrm{GA}_{2} \mathrm{TGCG}_{2} \mathrm{C}_{2} \mathrm{GCT}_{2} \mathrm{GCA}_{2} \mathrm{CGAT}_{4}$ \\
\hline PRH-3543 & Clone fliC pT7HMT-BamHI & $\mathrm{TACGCG}_{2} \mathrm{ATC}_{2} \mathrm{ATG}_{2} \mathrm{CACA}_{2} \mathrm{GTCAT}_{2} \mathrm{~A}_{2} \mathrm{TACA}_{2}$ \\
\hline PRH-3844 & Clone fliC pT7HMT-NotI & $\mathrm{ATA}_{2} \mathrm{GAT}_{2} \mathrm{GCG}_{2} \mathrm{C}_{2} \mathrm{GCT}_{2} \mathrm{~A}_{2} \mathrm{CGCAGCAGAGA}$ \\
\hline PRH-3845 & Clone fliC 176-395 pT7HMT-BamHI & $\mathrm{TACGCG}_{2} \mathrm{ATC}_{2} \mathrm{GATG}_{2} \mathrm{CGCGCAGA}_{3}$ \\
\hline PRH-3851 & Clone fliC 176-395 pT7HMT-NotI & $\mathrm{ATA}_{2} \mathrm{GAT}_{2} \mathrm{GCGGC}_{2} \mathrm{GCTCAT}_{2} \mathrm{GCA}_{2} \mathrm{CGAT}_{4}$ \\
\hline PRH-3971 & Clone fliC pCMV-XhoI & $\mathrm{TAC}_{2} \mathrm{GCTCGAG}_{2} \mathrm{CACA}_{2} \mathrm{GTCAT}_{2} \mathrm{~A}_{2} \mathrm{TACA}_{3} \mathrm{CAGC}_{2}$ \\
\hline
\end{tabular}

\subsection{Immunoblotting}

HCT-8 cell pellets were resuspended in $10.0 \mathrm{mM}$ HEPES, $1.5 \mathrm{mM} \mathrm{MgCl} 2,10.0 \mathrm{mM} \mathrm{KCl}, 0.5 \mathrm{mM}$ DTT, $0.05 \%$ NP-40 containing protease inhibitor cocktails (Thermo Scientific) and incubated on ice for $30 \mathrm{~min}$. Lysates were centrifuged $\left(10,000 \times g, 4{ }^{\circ} \mathrm{C}, 10 \mathrm{~min}\right)$ and the supernatant was collected. Immunoblotting was carried out as previously described [14] by separating proteins using $10 \%$ SDS-PAGE and then transferring the proteins to nitrocellulose membranes. Membranes were blocked in Odyssey blocking buffer (Li-Cor, Lincoln, NE, USA) at room temperature for $1 \mathrm{~h}$, and then incubated with appropriate primary and secondary primary antibodies. Immunoblots were developed using the Odyssey infrared imaging system (Li-Cor). Tubulin abundance was used to normalize IkB $\alpha$ abundance.

\subsection{Statistical Analysis}

For all quantitative data, tubulin immunoblotting was used to normalize I $\kappa \mathrm{B} \alpha$ abundance. The data represent at least 3 independent experiments and were analyzed using one-way ANOVA with the Dunnett's multiple comparisons test. Asterisks indicate significantly different IKB $\alpha$ abundance 
as compared with the 'TNF only' lane. Statistical differences were evaluated using one-way ANOVA with the Dunnett's multiple comparisons test. $p$-values $<0.05$ were considered significant.

Acknowledgments: This work was supported by grants AI101231, AI111203 and AI113552 from the National Institute of Allergy and Infectious Diseases. Its contents are solely the responsibility of the authors and do not necessarily represent the official views of the NIAID. The funding sponsors had no role in the design of the study; in the collection, analyses, or interpretation of data; in the writing of the manuscript, and in the decision to publish the results.

Author Contributions: G.W. and B.V.G. performed the experiments; B.V.G., C.R. and P.R.H. analyzed the data; G.W. and P.R.H. wrote the paper.

Conflicts of Interest: The authors declare no conflict of interest.

\section{Abbreviations}

$\begin{array}{ll}\text { ETEC } & \text { enterotoxigenic Escherichia coli } \\ \text { LT } & \text { heat-labile enterotoxin } \\ \text { NF-кB } & \text { nuclear factor-kB } \\ \text { ST } & \text { heat-stable enterotoxin } \\ \text { TNF } \alpha & \text { tumor necrosis factor } \alpha\end{array}$

\section{References}

1. Qadri, F.; Svennerholm, A.M.; Faruque, A.S.; Sack, R.B. Enterotoxigenic Escherichia coli in developing countries: Epidemiology, microbiology, clinical features, treatment, and prevention. Clin. Microbiol. Rev. 2005, 18, 465-483. [CrossRef] [PubMed]

2. Giddings, S.L.; Stevens, A.M.; Leung, D.T. Traveler's Diarrhea. Med. Clin. N. Am. 2016, 100, 317-330. [CrossRef] [PubMed]

3. Fleckenstein, J.M.; Hardwidge, P.R.; Munson, G.P.; Rasko, D.A.; Sommerfelt, H.; Steinsland, H. Molecular mechanisms of enterotoxigenic Escherichia coli infection. Microbes Infect. 2010, 12, 89-98. [CrossRef] [PubMed]

4. Madhavan, T.P.; Sakellaris, H. Colonization factors of enterotoxigenic Escherichia coli. Adv. Appl. Microbiol. 2015, 90, 155-197. [PubMed]

5. Huang, D.B.; DuPont, H.L.; Jiang, Z.D.; Carlin, L.; Okhuysen, P.C. Interleukin-8 response in an intestinal HCT-8 cell line infected with enteroaggregative and enterotoxigenic Escherichia coli. Clin. Diagn. Lab. Immunol. 2004, 11, 548-551. [CrossRef] [PubMed]

6. Haiko, J.; Westerlund-Wikstrom, B. The role of the bacterial flagellum in adhesion and virulence. Biology (Basel) 2013, 2, 1242-1267. [CrossRef] [PubMed]

7. Zhou, M.X.; Duan, Q.D.; Zhu, X.F.; Guo, Z.Y.; Li, Y.C.; Hardwidge, P.R.; Zhu, G.Q. Both flagella and F4 fimbriae from $\mathrm{F} 4 \mathrm{ac}(+)$ enterotoxigenic Escherichia coli contribute to attachment to IPEC-J2 cells in vitro. Vet. Res. 2013, 44, 30. [CrossRef] [PubMed]

8. Zhou, M.X.; Guo, Z.Y.; Yang, Y.; Duan, Q.D.; Zhang, Q.; Yao, F.H.; Zhu, J.; Zhang, X.J.; Hardwidge, P.R.; Zhu, G.Q. Flagellin and F4 fimbriae have opposite effects on biofilm formation and quorum sensing in F4ac+enterotoxigenic Escherichia coli. Vet. Microbiol. 2014, 168, 148-153. [CrossRef] [PubMed]

9. Roy, K.; Hilliard, G.M.; Hamilton, D.J.; Luo, J.W.; Ostmann, M.M.; Fleckenstein, J.M. Enterotoxigenic Escherichia coli EtpA mediates adhesion between flagella and host cells. Nature 2009, 457, 594-598. [CrossRef] [PubMed]

10. Lawrence, T. The nuclear factor NF-kappaB pathway in inflammation. Cold Spring Harb. Perspect. Biol. 2009, 1, a001651. [CrossRef] [PubMed]

11. Karin, M.; Ben-Neriah, Y. Phosphorylation meets ubiquitination: The control of NF-[kappa]B activity. Annu. Rev. Immunol. 2000, 18, 621-663. [CrossRef] [PubMed]

12. Yin, Q.; Fu, T.M.; Li, J.; Wu, H. Structural biology of innate immunity. Annu. Rev. Immunol. 2015, 33, $393-416$. [CrossRef] [PubMed]

13. Reddick, L.E.; Alto, N.M. Bacteria Fighting Back: How Pathogens Target and Subvert the Host Innate Immune System. Mol. Cell 2014, 54, 321-328. [CrossRef] [PubMed]

14. Wang, X.; Hardwidge, P.R. Enterotoxigenic Escherichia coli prevents host NF-kappaB activation by targeting IkappaBbalpha polyubiquitination. Infect. Immun. 2012, 80, 4417-4425. [CrossRef] [PubMed] 
15. Planesse, C.; Nativel, B.; Iwema, T.; Gasque, P.; Robert-Da Silva, C.; Viranaicken, W. Recombinant human HSP60 produced in Clearcoli (TM) BL21(DE3) does not activate the NF kappa B pathway. Cytokine 2015, 73, 190-195. [CrossRef] [PubMed]

16. Maki-Yonekura, S.; Yonekura, K.; Namba, K. Conformational change of flagellin for polymorphic supercoiling of the flagellar filament. Nat. Struct. Mol. Biol. 2010, 17, 417-422. [CrossRef] [PubMed]

17. Li, H.X.; Lin, X. Positive and negative signaling components involved in TNF alpha-induced NF-kappa B activation. Cytokine 2008, 41, 1-8. [CrossRef] [PubMed]

18. Fotin-Mleczek, M.; Welte, S.; Mader, O.; Duchardt, F.; Fischer, R.; Hufnagel, H.; Scheurich, P.; Brock, R. Cationic cell-penetrating peptides interfere with TNF signalling by induction of TNF receptor internalization. J. Cell Sci. 2005, 118, 3339-3351. [CrossRef] [PubMed]

19. Evans, D.G.; Silver, R.P.; Evans, D.J., Jr.; Chase, D.G.; Gorbach, S.L. Plasmid-controlled colonization factor associated with virulence in Escherichia coli enterotoxigenic for humans. Infect. Immun. 1975, 12, 656-667. [PubMed]

20. Geisbrecht, B.V.; Bouyain, S.; Pop, M. An optimized system for expression and purification of secreted bacterial proteins. Protein Expr. Purif. 2006, 46, 23-32. [CrossRef] [PubMed]

21. Datsenko, K.A.; Wanner, B.L. One-step inactivation of chromosomal genes in Escherichia coli K-12 using PCR products. Proc. Natl. Acad. Sci. USA 2000, 97, 6640-6645. [CrossRef] [PubMed]

22. Gao, X.F.; Wan, F.Y.; Mateo, K.; Callegari, E.; Wang, D.; Deng, W.Y.; Puente, J.; Li, F.; Chaussee, M.S.; Finlay, B.B.; et al. Bacterial Effector Binding to Ribosomal Protein S3 Subverts NF-kappa B Function. PLoS Pathog. 2009, 5, e1000708. [CrossRef] [PubMed]

(C) 2017 by the authors. Licensee MDPI, Basel, Switzerland. This article is an open access article distributed under the terms and conditions of the Creative Commons Attribution (CC BY) license (http:/ / creativecommons.org/licenses/by/4.0/). 